\title{
Caring Decisions: The Development of a Written Resource for Parents Facing End-of-Life Decisions
}

\author{
Vicki Xafis, BA (Languages, H1 Hons-Linguistics), RSA (DTEFLA), MBioethics, PhD, 1,2 \\ Lynn Gillam, BA (Hons), MA (Oxon), PhD, ${ }^{3,5}$ Jenny Hynson, MBBS, FRACP, PhD, \\ Jane Sullivan, BSW, BA, Grad Dip Adol \& Ch Psych, BTheol, MSW, PhD, 3,5 \\ Mary Cossich, MBBS, MPC, FRACP, FAChPM, ${ }^{6}$ \\ and Dominic Wilkinson, MBBS, BMedSci, MBioeth, DPhil, FRACP, FRCPCH $\mathrm{H}^{1,7,8}$
}

\begin{abstract}
Background: Written resources in adult intensive care have been shown to benefit families facing end of life (EoL) decisions. There are few resources for parents making EoL decisions for their child and no existing resources addressing ethical issues. The Caring Decisions handbook and website were developed to fill these gaps. Aim: We discuss the development of the resources, modification after reviewer feedback and findings from initial pilot implementation.

Design: A targeted literature review-to identify resources and factors that impact on parental EoL decisionmaking; development phase-guided by the literature and the researchers' expertise; consultation processcomprised a multi-disciplinary panel of experts and parents; pilot evaluation study-hard-copy handbook was distributed as part of routine care at an Australian Children's Hospital.

Setting/Participants: Twelve experts and parents formed the consultation panel. Eight parents of children with life-limiting conditions and clinicians were interviewed in the pilot study.

Results: Numerous factors supporting/impeding EoL decisions were identified. Caring Decisions addressed issues identified in the literature and by the multidisciplinary research team. The consultation panel provided overwhelmingly positive feedback. Pilot study parents found the resources helpful and comforting. Most clinicians viewed the resources as very beneficial to parents and identified them as ideal for training purposes. Conclusions: The development of the resources addressed many of the gaps in existing resources. The consultation process and the pilot study suggest these resources could be of significant benefit to parents and clinicians.
\end{abstract}

\section{Introduction}

D ECISIONS about life-sustaining medical treatment are common in pediatric and neonatal care and are known to be difficult and stressful for families. ${ }^{1-5}$ Despite the support of medical and nursing staff, ${ }^{2,5-11}$ parents often seek additional information from other sources ${ }^{5,8,9,11-17}$ to assist with difficult end-of-life (EoL) decisions.

Written resources articulated in simple nontechnical language could enable parents to process information at their

\footnotetext{
${ }^{1}$ Discipline of Obstetrics and Gynaecology, Women's and Children's Hospital, The University of Adelaide, Adelaide, Australia.

${ }^{2}$ The Sydney Children's Hospitals Network, Westmead, New South Wales, Australia.

${ }^{3}$ Children's Bioethics Centre, ${ }^{4}$ Victorian Paediatric Palliative Care Program, The Royal Children's Hospital, Melbourne, Australia.

${ }^{5}$ Centre for Health Equity, University of Melbourne, Melbourne, Australia.

${ }^{6}$ Disciplines of Palliative Medicine and General Paediatrics, Women's and Children's Health Network, Adelaide, Australia.

${ }^{7}$ Medical Ethics Department, Oxford Uehiro Centre for Practical Ethics, Oxford University, Oxford, United Kingdom.

${ }^{8}$ John Radcliffe Hospital, Oxford, United Kingdom.

Accepted June 30, 2015.
}

(C) Vicki Xafis, Lynn Gillam, Jenny Hynson, Jane Sullivan, Mary Cossich, Dominic Wilkinson 2015; Published by Mary Ann Liebert, Inc. This Open Access article is distributed under the terms of the Creative Commons Attribution Noncommercial License (http:// creativecommons.org/licenses/by-nc/4.0/) which permits any noncommercial use, distribution, and reproduction in any medium, provided the original author(s) and the source are credited. 
own pace and better enable them to raise issues important to them with their child's health care team. In adult intensive care, written resources for families have been found to have a positive impact on the comprehension of medical facts relating to diagnoses and treatment ${ }^{18}$ and on families' ability to deal with distress after the death of a relative. ${ }^{19}$ Parents who have faced EoL decisions have indicated that information needs to be repeated, as it is understood and processed incrementally. ${ }^{20}$ Written resources could help parents better understand information. However, there are currently limited reliable independent sources of written information, ${ }^{21-23}$ and there are no existing resources for parents that address the complex ethical questions involved in EoL decisions.

The Caring Decisions handbook ${ }^{24}$ and associated web-based resource $^{25}$ were developed specifically to fill these gaps. This paper provides insight into the development of the resources, modifications after reviewer feedback, and findings from initial pilot implementation.

\section{Methods}

\section{Targeted literature review}

We conducted a literature search and undertook a metasynthesis of predominantly empirical research that discussed factors that are helpful and unhelpful in parental EoL decision making. ${ }^{26}$

\section{Development}

The drafting of sections appropriate for a shorter hardcopy handbook and longer web version commenced in parallel in February 2013 and was completed in September 2013. Materials were reviewed iteratively by members of a multidisciplinary team with expertise in neonatology, pediatric palliative care, social work, bioethics, and linguistics. Permission was sought from parents who had been interviewed as part of a previous research project ${ }^{27}$ to use some of their quotations in the resources. The parents were also invited to review the draft material.

\section{Consultation phase}

Draft versions of the handbook were distributed to parents who had made EoL decisions and had experienced the death of a child, medical practitioners (including neonatal and pediatric intensive care clinicians, palliative care physicians), indigenous family support workers, nurses, bioethicists, parent support organisations, and international clinical experts.

\section{Initial evaluation}

A pilot evaluation study commenced at an Australian capital city hospital and involved the neonatal and pediatric intensive care units and the children's palliative care service at that hospital following ethics approval from the hospital ethics committee. The study received ethics approval from the hospital ethics committee in early September 2013. Information sessions commenced in late September 2013 and were repeated in February 2014 to ensure that health care professionals were familiar with the research. The hardcopy handbook was made available to the units along with pertinent research information. Permission to disseminate the hardcopy handbook as part of routine care was sought from departmental heads. Health care professionals were asked to distribute the handbook to parents with whom they were having EoL discussions, where appropriate. Parents were invited to meet with the research team and undertake an interview in person within a short time following EoL discussions. For infants or children who had died, interviews were planned to be delayed for six weeks. Data were collected via parent and clinician interviews and were transcribed thematically.

\section{Results}

\section{Literature review}

We found limited literature specifically on written information needs for parents facing EoL decisions for their child. We therefore reviewed factors identified by parents themselves as supporting or impeding EoL decisions ${ }^{26}$ with a view to addressing these needs in the resources we were developing.

\section{Development}

We developed a printed handbook in question/answer format also containing parent narratives describing their experience with EoL decisions for their child, example questions parents can ask, and a notes section. The content of the handbook was guided by the results of the targeted literature review, and by clinical experience in talking with parents in these sorts of situations. Table 1 illustrates how the literature was used to address parental needs in the handbook. The handbook was brief so that parents would not be overwhelmed with detailed information at a time when they were first considering EoL decisions for their child. A longer webbased version was also developed in question/answer format and provided more detailed responses, narratives, and material from parents.

\section{Consultation process}

Twelve responses were received from national and international health care professionals (including two who provided perspectives of different faiths), parent support groups, and indigenous family support workers and six from parents who had themselves made EoL decisions. The feedback was overwhelmingly positive (see online supplementary Table S1 at www.liebertpub.com/jpm and at www.liebertonline.com), and some reviewers had few suggestions to make, as they felt that the resources were of a high standard. Other reviewers made experience-based suggestions on a number of aspects such as content, linguistic features (format, length etc.), impact of the materials on readers, and more general comments. The resources were modified in light of the reviewers' suggestions. One reviewer raised the issue of whether there was appropriate balance in the information, which we then further considered. ${ }^{61}$ The final topics included in the web resource, after the consultation process, are displayed in Table 2.

\section{Pilot evaluation study}

In total, the handbook was offered to 12 families (see Table 3). Of these 12 families, two parents of children with life-limiting conditions from two separate families were interviewed and no parents of children who had died were recruited. In addition, six clinicians provided feedback via face-to-face interviews. 
Table 1. Caring Decisions: Responding to Parental Needs and Requests AS DESCRIBED IN THE Literature

Aspects parents

comment on or consider

Written resources

Sources of information

Technical understanding

Inability to articulate questions

Jargon

Amount of information

Delivery of information

Others' experiences

Support/development of a trusting relationship

Conflicting information and disagreement

Key findings

Response in Caring Decisions resources to issues raised by parents

Parents have indicated that written resources in the form of pamphlets or booklets help them retain information [28, 29].

While parents rely heavily on healthcare professionals for accurate and relevant information, they also seek information from other sources including the internet $[5,8,9,11-17]$.

Parents' lack of scientific knowledge can lead them to later doubt the decisions they made for their child [30]. Parents' lack of understanding of medical issues reduces their willingness to make decisions for their child and prompts them to leave the decision-making to healthcare professionals [1, 31, 32].

Not knowing what to ask caused parents to have access to less information vital for decisionmaking [33-35].

Parents in numerous studies indicate that medical jargon is confusing and overpowering. This impacts on parents' ability to properly assess the information required for them to make decisions [10, 34-38].

Many parents complained about the paucity of information provided. Parents felt that a lack of information impacted on their ability to make decisions. Some parents felt that they would have made different decisions if they had had access to more information [12, 34, 35, 39-41].

Parents are very sensitive to the manner with which bad information is delivered and when they perceive doctors to be uncaring, it causes distress and distrust. Parents want information to be simple, honest, and delivered compassionately. Such information delivery reduces their fear, increases their sense of control, and aids in their decision-making [37, 42-45].

Parents have expressed the view that talking to other parents with similar experiences would have helped them cope better with their decisions, would have prepared them better for future events, or would have impacted on the decisions that they made $[2,46]$.

Parents who felt supported, not judged, and whose situation was acknowledged as being difficult tended to trust healthcare professionals more and tended to be able to cope with the decisions they had made. Lack of support from healthcare professionals expressed in a range of ways, such as uncaring or disrespectful attitudes, caused distress in parents. Emotional distress is known to affect decision-making [2, 8, 13, 15, 37, 38, 42].

Parents are disturbed by conflicting information from healthcare professionals and disagreement between parents and clinicians led to difficult relationships [8, 37, 38, 42, 43, 47, 48].
Development of written information in the form of a small printed handbook with room for parents to make notes.

Development of detailed web-based resource, made freely available on the internet (as well as printable, downloadable version of shorter handbook).

Inclusion of easy-to-understand definitions of key terms (e.g. life support treatment, comfort treatment etc.) as well as clarification of key medical information (e.g. explanation of various kinds of life support treatments).

Inclusion of example questions/phrases that parents could ask or draw on when speaking to healthcare professionals.

Simplified language (also examined by independent Plain Language Officer).

Web resource contains more detailed information, allowing parents to find additional information if required.

Resources discuss difficult issues sensitively, but also openly and honestly. Feedback from parents and parent support groups was sought.

Parent narratives provide readers with insight and an understanding of the circumstances under which decisions were made, parents' considerations, difficulties, and ways of coping with their circumstances.

The text is fully supportive of parents and acknowledges their pain, distress, and emotional turmoil and in doing so shows them respect. The resources also encourage parents to talk to healthcare professionals and discuss their concerns, values, and thoughts.

Includes section that explains how disagreements between healthcare professionals may come about. The section also discusses other areas of disagreement, i.e. parent/clinician disagreement, mother/father disagreement, parent/ family disagreement. Some potential approaches to resolving disagreement are provided.

(continued) 
TABle 1. (CONTINUED)

\begin{tabular}{|c|c|c|}
\hline $\begin{array}{l}\text { Aspects parents } \\
\text { comment on or consider }\end{array}$ & Key findings & $\begin{array}{c}\text { Response in Caring Decisions resources } \\
\text { to issues raised by parents }\end{array}$ \\
\hline Uncertainty & $\begin{array}{l}\text { Some parents are aware that there is sometimes } \\
\text { uncertainty in prognoses and treatment. Parents } \\
\text { want to know when healthcare professionals are } \\
\text { faced with uncertainty and want to know when } \\
\text { doctors have dilemmas }[3,44,48,49] \text {. }\end{array}$ & $\begin{array}{l}\text { The resources discuss the uncertainty of } \\
\text { some diagnoses and prognoses. Such } \\
\text { understanding may prompt parents to } \\
\text { ask about the level of clinicians' cer- } \\
\text { tainty and encourage an open discus- } \\
\text { sion of their child's circumstances. }\end{array}$ \\
\hline $\begin{array}{l}\text { Involvement in } \\
\text { decision-making }\end{array}$ & $\begin{array}{l}\text { Extensive literature indicates that parents' prefer- } \\
\text { ences regarding involvement in decision-making } \\
\text { vary widely on a scale of no involvement through } \\
\text { to involvement in discussions but not decisions, } \\
\text { shared decision-making, to full parental respon- } \\
\text { sibility for decisions. Numerous studies indicate } \\
\text { that some parents do not want to have full } \\
\text { responsibility for the decisions they make. } \\
\text { Reluctance to make decisions [1, 50, 51]; } \\
\text { Involvement in discussions but not decisions [31, } \\
\text { 45]; Shared decision-making [20, 30, 35, 42, 43, } \\
\text { 52-56]; Parents' responsibility [4, 7, 30, 38, 57, } \\
\text { 58]; Not full responsibility [31, 32, 42, 45, 51-53] }\end{array}$ & $\begin{array}{l}\text { Includes section discussing the many } \\
\text { stances parents adopt in decision-mak- } \\
\text { ing. The section acknowledges the } \\
\text { difficulty of the task and tries to } \\
\text { empower parents by encouraging them } \\
\text { to discuss their preferences with } \\
\text { healthcare professionals. Sample ques- } \\
\text { tions and phrases appropriate for this } \\
\text { topic are provided. }\end{array}$ \\
\hline Quality of life & $\begin{array}{l}\text { Parents considered it important to take into account } \\
\text { their child's quality of life when making end-of } \\
\text { life decisions. However, using such a criterion } \\
\text { was very difficult for them }[4,59,60] \text {. }\end{array}$ & $\begin{array}{l}\text { The handbook provides a definition, a } \\
\text { consideration of the importance of taking } \\
\text { quality of life into account, and a parent } \\
\text { quote. The web resource dedicates an } \\
\text { extensive section covering many aspects } \\
\text { relating to quality of life and includes } \\
\text { questions parents can ask clinicians. }\end{array}$ \\
\hline
\end{tabular}

The low numbers were partly due to the low rate of EoL discussions at the participating hospital units during the recruitment period, which ran from October 2013 to June 2014. For example, in one of the intensive care units of the participating hospital, five babies died between October 1, 2013 and June 30, 2014 compared to the corresponding period in the previous year during which 11 babies died.

\section{Key themes-Parent feedback}

The parents interviewed used the resources in different ways. The father accessed only the hardcopy handbook and read it numerous times while the mother read the hardcopy handbook once and accessed the web resource later. Both parents felt that the resource was helpful, particularly the parent narratives.

$$
\begin{aligned}
& \text { "... they were in the same boat as me ... I really liked reading } \\
& \text { about some of the experiences that other parents have had in } \\
& \text { the past ..." } \\
& \text { "I suppose given the situation, you don't know what to expect } \\
& \text { so when I read it, yeah, trying to get an idea of what other } \\
& \text { people have been through and that." }
\end{aligned}
$$

Both parents resorted to reading the resources to cope with the difficult and uncertain circumstances they were faced with. They got a sense of what to expect in the future, and the mother reported feeling better emotionally prepared for future decisions for her child after reading the resources, and less afraid of the unknown.

“... To be honest with you, that's what scares me the most as a parent-like not knowing what to expect.... Look, for me I was grateful [to have read the resources] because I like to feel-not in control, but I like to feel organized enough that I'll be able to cope with the situation when it arrives."

For the mother, reading the resources alleviated her sense of guilt about decisions made.

“I personally, I feel like I'm giving up on him ... But ... [the handbook] clarified that it's quite normal to feel that way.... That helped me because that's something big that I'm dealing with, ... that guilt."

Both parents found the material easy to understand, relevant, and felt the material covered the most important issues. Difficult and confronting information such as the description of extubation, was felt to have been conveyed sensitively and 'tastefully.' The father would have liked material on caring for his child at home.

The conflict between strong opposing interests was also covered in the resources. The mother was helped by reading parent quotations about this and content on the challenge of recognizing and disentangling opposing interests.

“... there was one quote in there where you have to draw a line in the sand and if they step over that line you know that there's no coming back from that sort of thing. You have to let them go for their own good, not just because you want them here and stuff like that."

Neither of the parents accessed other resources to help with decision making and "Caring Decisions" was not relied on for decision making, as the mother had made decisions with health care professionals before receiving the resources, whereas the father was guided by health care professionals. 
Table 2. Topics Covered in the Parent Resource Caring Decisions

\begin{tabular}{l}
\hline Chapter heading \\
\hline Introduction \\
How do parents think about \\
end-of-life decisions \\
Life support treatment \\
Comfort treatment and \\
palliative care \\
Stopping life support
\end{tabular}

Stopping and not starting

Different types of
treatment

Doing what is best

Quality of life

Uncertainty Who decides about
life support?

Disagreement

Religion, culture, and life support

After a decision

Taboo questions

What to tell other people

\section{Further information}

Subsections in each chapter

How common are decisions about life support for children? Why should I read this handbook? Is this handbook relevant for my child? How should I read this book? Why am I being asked these questions? It is not given to me to decide about life? Starting a conversation with your child's doctors. 'The bigger picture.' There is too much to think about ... I don't understand ... Support at a stressful time. Terms used in this handbook. Nil

What is life support treatment? Are there different types of life support treatment?

What is comfort treatment and palliative care? Is palliative care just for children who are dying?Can a child have comfort treatment and life support treatment?

Why would doctors want to stop life support treatments for my child? Are there different reasons for stopping or not starting life support treatment? Is it legal to stop or not start life support treatment? Is stopping treatment euthanasia? What is futile medical treatment? Futile treatment and the dying process. Questions you could ask.

Is there a difference between stopping treatment and not starting treatment? What if I still feel uncomfortable stopping life support treatment for my child? What is a 'trial of life support treatment'? Questions that you could ask your child's doctors about treatment.

Are decisions different for different life support treatments? Is it OK to stop some life support treatments but continue others? What is a DNAR or AND order? If I agree to a DNAR order for my child will other people know? What will other people think of me if I agree to a DNAR for my child? If I agree to a DNAR will other treatment stop? What if I change my mind? What if I decide that I want doctors and nurses to provide CPR for my child? I want everything to be done. Is it OK to stop artificial feeding? Is it legal to stop artificial feeding?

What is the right thing to do? How do we work out what would be best? Should I ask my child? What if my child doesn't want life support treatment?

What is 'quality of life'? Is it appropriate to use quality of life when making decisions for children? Are all 'quality of life' decisions the same? Are 'quality of life' decisions different in children? What about the 'sanctity of life' approach? Isn't life sacred? Is it discriminatory to stop life support treatment based on 'quality of life'? Is quality of life a 'personal' decision? Questions you could ask your doctor.

Can the doctors be certain about what will happen for my child? Questions you could ask your doctor about uncertainty. Ways to think about uncertainty. Is there a rush to make a decision? Do I need to decide now? I have read about a new treatment/test on the Internet.

Who makes the final decision about life support treatment? What does shared decision making mean? Questions you might like to ask your doctor. Phrases that may be helpful. What if I don't want to decide? Do parents need to consent to stopping treatment? What would you do, doctor?

What should I do if the doctors don't agree about life support? What should I do if I don't agree with my child's doctors about life support? What should I do if my partner and I do not agree about life support treatment? What should I do if others in my family do not agree about life support treatment?

Is it against my religion to stop life support? Is it playing God to stop life support? What about the sanctity of life? I don't want to stop life support because I am waiting for a miracle. Can I talk to my doctor about my cultural or religious beliefs? Can I ask doctors to speak to my elder or religious advisor? What do different religions say about stopping life support?

We have decided to continue life support. What will happen now? We have decided to stop or not start life support. What will happen now? What happens after a breathing tube is removed? If my child has morphine, will it stop him/her breathing? How long do we have? What about organ or tissue donation? What do I do about organizing a funeral?

What if I had ...? If only I had. ... Is it bad to wish for my child to die? Can't the doctors give my child something to put them out of their misery? Do doctors want to stop life support for my child because it costs too much? Is stopping life support treatment giving up on my child? Is there no hope? The doctors cannot be right. They must have made a mistake. If I agree to stop life support, will people think I am a bad parent? Will we be abandoned? Will I be letting the doctors down if I agree to stopping or not starting life support? What about the rest of my family and their quality of life?I am afraid that I won't be able to cope if.... Did I make the right decision? Will I be able to live with myself?

Should I say anything? What do I tell other people about life support? What do I tell my other children?

\footnotetext{
${ }^{\mathrm{a}}$ www.rch.org.au/caringdecisions/.
} 
Table 3. Distribution of Handbook to Families Facing Eol Decisions during Pilot Evaluation Study

\begin{tabular}{lcl}
\hline Distribution to families & No. of families & Factors cited by medical staff as influencing distribution \\
\hline Handbook given & 10 & n/a \\
Handbook offered but declined & 2 & One family had limited English \\
Unknown if handbook given & 4 & n/a \\
Handbook not given & 3 & One family had limited English \\
& & Difficult EoL discussions with family \\
& Lack of time due to sudden death of the child
\end{tabular}

\section{Key themes-Clinician feedback}

Clinicians felt the resources would empower parents. The resources clarified medical terms and aspects of care that are often not understood adequately as well as parental concerns that do not necessarily immediately arise in clinicians' thinking. Clinicians felt that the resources were of a high standard and that they addressed a wide array of difficult issues accurately, sensitively, and in sufficient breadth and depth. The content was considered to be true to life while also analyzing important ethical issues in an accessible manner. The inclusion of real-life narratives and topics such as guilt, loneliness, conflict with family etc. were seen as very helpful (see Table 4 for more quotes).

"I think because each section has a couple of ideas built into it I think that's not confronting in that sense then. So it lets people sort of gently see where it's trying to go." Clinician-2

"I love the way it gives it all to the parents and gives them the right words to use and how to engage and all of that ... because of that engagement process I think it gives parents tools that they can then go and ask the doctors questions..." Clinician-5

The content and the parent narratives were viewed as valuable in reducing the sense of isolation that parents sometimes experience. The resources were also seen as potentially reducing parents' sense of powerlessness and guilt associated with making such difficult decisions for their child despite the well established shared decision making models now adopted in most contexts.

"... I think that there is a lot of things in there that probably answer a lot of their questions and could potentially alleviate their feeling of guilt, to say they've done the right thing by looking at other people's experience." Clinician-6

Although the resources were developed primarily for parents, clinicians felt the topics had sufficient breadth and depth and would be useful to clinicians. Five clinicians saw great benefits in their use in training and provided some insight into the ways the resources could be used to assist in developing less experienced clinicians' understanding and expertise.

"I would happily use this as a resource in training our own trainees ... Because it is quite a lucid exposition of the problems, with the perspective of parents..." Clinician-3

The inclusion of questions parents can ask clinicians was considered valuable, as they enable clinicians to consider their responses in advance.
“... I found it nice to actually go through the resource and look at some of those issues ... the questions that might come up and how I would handle those questions as well ... So it helps me prepare for such a conversation as well. "Clinician-5

Two more experienced clinicians felt the resources were not particularly useful to them personally. However, one felt that the resources would be beneficial to other specialities and subspecialties caring for children with ongoing life-limiting health conditions.

\section{Barriers to dissemination}

Certain factors led to difficulties in disseminating the resources during the study. For example, clinicians referred to the unusually low number of children suffering from lifelimiting conditions in the second half of 2013 and first half of 2014 as a factor. Some clinicians held reservations about having EoL discussions and simultaneously broaching the topic of research and consequently did not distribute the handbook. One clinician expressed concerns about such resources delaying decision making and disrupting clinicians' efforts to obtain parental consent, but another recognized that delayed decisions are usually better ones. Difficulties ascertaining the appropriate timing for distribution of the handbook were also noted.

\footnotetext{
"I think that it is hard to actually give out the book and talk about research in the same ..." Clinician-1

"I think it might [delay decision making], but at the end of the day I think it would end up being a better decision. I think we don't realize the long-term impact on families about decisions that we make quickly and we move on and we forget that ..." Clinician-5
}

\section{Resources}

One clinician made specific comments on the existing layout, content, and style and suggested placing the first real-life narrative later in the handbook, as parents might find it confronting. It was noted that there was no material for children old enough to participate in discussions about their own life and another noted there were no narratives regarding 'messy' discussions where there was disagreement about decisions.

\section{Discussion}

Deaths in pediatric and neonatal intensive care usually result from decisions to withhold or withdraw treatments, ${ }^{62-65}$ and parents rely on information from clinicians in their decision making. Similar decisions may be faced outside the intensive care unit, for example, for children with life-limiting illness in 
Table 4. Clinicians' Views on Usefulness of Caring Decisions Resources

Stakeholders

benefiting

Parents

Experienced clinicians

\author{
Clinician quotes
}

I'm positive about how it might be used and the effects that it might have, and especially in allowing parents to order their thoughts and not be unduly influenced by what are sometimes not that lengthy discussions about these sort of matters. So I see it as a positive initiative.... I think in general the clarity and helping people to order their thoughts, because the parents do say that there's so much information and it's so difficult to get it into the right order. They're being expected to apply that information to the life of their child, and that's very difficult for them. Clinician-3

I love the way it gives it all to the parents and gives them the right words to use and how to engage and all of that.... Because of that engagement process I think it gives parents tools that they can then go and ask parents, ask the doctors questions, do you know what I mean? Clinician-5

I would want them to have as much information as possible. So I would see these resources as something I could use in conjunction with my meetings with them. Something solid and concrete they could take away and something that they could ... another resource that they could access if they wanted to go deeper into a particular aspect. Clinician-3

Do you think that this resource would assist in those cases or do you think, as some have indicated, that it might potentially delay decision making? (Interviewer)

I think it might, but at the end of the day I think it would end up being a better decision. I think we don't realize the long-term impact on families about decisions that we make quickly and we move on and we forget that-and over the years I've seen a number of cases of parents that were clearly scarred badly by what happened. Clinician-5

I think consultants might just often ask, 'Do you have any more questions?' and parents may not have any, but having something with them where they can just read at their own pace and then come back, especially if time allows. ... Yeah and I think they also get an idea about these terms that we often take for granted, they may not be in a layperson's vocabulary that much and maybe they don't want to look embarrassed by asking, What does that mean? What does that term mean? Whereas in the book I think they're quite well explained in a layperson's language. Clinician-6

Look, it may actually be helpful because often people don't fully take in what you're talking about. So I don't think it would be harmful at all. It may be quite good to see something in writing that somebody has been talking about. When you're having a one-on-one conversation you're just one person and I guess they want to be reassured that what you're saying is reflecting an accepted view. I guess the print brings some sort of credibility to that. I don't think the way it was written was wrong at all. Clinician-1

It's nice to just have those bits that feel personal, because you always feel like someone's been there. I'm not the only one. When I look at it as a parent, you at least feel that personal touch, that these are real people who have been through this and I'm not the only person going through this. I think that's really nice. Clinician-4

Look, the more I read I thought it was really good and I could see someone at a bedside or just at home with nothing to do and everything's going around in their head sort of getting onto that website and just going I want to know about that, I want to know about that, oh that's an interesting ... like the taboo topics, what's that and even for that you think, Oh, that's exactly what I'm thinking. Clinician-5

Because there's the grief afterwards and I think it starts early on when the patient may still be alive, like to be prepared and having maybe this sense of control if they know the likely scenario that's going to happen. They read about other people's experience with it in a layperson's language, I think that might help them a lot.... Yeah, I think that there are a lot of things in there that probably answer a lot of their questions and could potentially alleviate their feeling of guilt, to say they've done the right thing by looking at other people's experience. Clinician-6

If they have the time to actually sit and think about it, and a resource that actually talks through it in a very nonconfrontational way. Because there's not a physical person talking about these individual things, but they get time to sit with this book or with the electronic resource and actually slowly think about the situation. Let it all unfold and absorb that, and then have their list of questions and go and talk to a person. Clinician-4

It might be beneficial for some other people who need to have these discussions a lot earlier. A lot of these patients who come in have been seen for years by general pediatricians and other subspecialists with clearly long-term progressive diseases which are clearly going to be life shortening. They should really be having these discussions early and frequently. I don't feel for me personally it's very useful because we have these conversations more than other people do. Clinician-1

Possibly for me I doubt it's changed all that much. I think we always like to think we're thoughtful and approachable and pragmatic and so I don't think necessarily, speaking personally, that that's [i.e., access to resources] changed anything for me. Clinician-2

It's not just knowing that it's okay and knowing that there are typical thoughts that will be running through families' minds but also having that interpersonal skill-set that allows you to listen carefully as opposed to impose your own values on things. Effective change requires more than just a website or a document. But we've got to start somewhere. Clinician-2 
TABle 4. (CONTINUED)

Stakeholders

benefiting
Clinician quotes

I think some of them [i.e., clinicians] in particular have a better understanding of the sort of situations and the resources that are available to families and how to answer some of the questions. Clinician-5

There are many different aspects to this problem and to this activity. To some extent, yes, it is important to grasp basic ethical principles which were not..none of us ... it's rare that a doctor has any formal training in philosophy or ethical thought. Likewise, in how that relates to legal aspects. So I think it is useful to have a resource that has a wide remit, where the net is spread wide. Certainly in our department it would be helpful in our day-to-day work. Clinician-3

So it was nice to have something that actually went through a lot of these important issues. Clinician-4

I guess we could activate this in order to finesse the terminal care aspects of it... I think we should have it as our template on how to do this. Clinician-5

But when you look at it the other way and from a parent's perspective, their anxieties, questions, their feelings, their guilt, what to expect, there's so many things that's going on there, which I think it's nice to ...for me I found it nice to actually go through the resource and look at some of those issues. How ... the questions that might come up and how I would handle those questions as well. ... So I think it's helpful for me as well, because it's things that you don't quite sit and think about, but you look at it and say, Hmm, the parents do think about these things. How would we-how would I respond to such a question, for example. So it helps me prepare for such a conversation as well. Clinician-4

It's really useful to just briefly introduce the concept of redirection of care, give them the time to really go through the resource, and then meet them again with trying to answer their questions or just going over some things in more detail and then looking at what would happen if you do this or that. I think that's a much better way of doing things. ... Because a lot of those things that we discuss in the book are not something that's easy to come out with in a conversation, especially if you're meeting a parent for the first time. It's not easy to talk about those things in such a difficult situation. So I think it's a gentle way of actually introducing a lot of important issues that a parent has to deal with. Then you can sort of use that as a base to start further discussions. Clinician-4

I think this is just as much use for health care professionals, I think, because of the way it deals with how you interact, how you engage the process. So I do think that those complicated and difficult things need to be taken out and looked at from all different angles, so people can appreciate that.... So I see the depth and breadth of the discussion in this as something that people that are in the profession should understand, certainly from where we are and obviously from all those other areas in medicine. Clinician-5

Trainees I think it's pretty quick and easy to read, isn't it, so it's not unreasonable for nurses and trainee specialists to read. I think it would be pretty good. Clinician-1

I would happily use this as a resource in training our own trainees. ... Because it is quite a lucid exposition of the problems, with the perspective of parents, and it would be a useful training tool, I think. Certainly in our department it would be helpful in our day-to-day work, but also in our training of junior staff. Clinician-3

I certainly think it would be useful. It would be useful just to even have, Oh, these are the things that come up. How would you approach it? Just to have a discussion based on the things that the book talks about. I think it would be a useful teaching resource as well. Clinician-4

We see this as core to their training and, in fact, all of the issues brought out in the various chapters are things they really need to see. Because these are young people, they haven't had children of their own. They're lovely, they're terrific, they're very bright but I think this brings out more of the humanity of the situation. Clinician-5

For me it would be a good guide, how to be prepared for these questions, because I myself haven't seen that many babies die. ... I wouldn't be very prepared, I mean predicting how things go and how long the dying process may work and also what other things mean. ... I've never seen a baby on whom nutrition was withdrawn, how long that may take. I don't have enough personal experience to guide the parents for that. So I think these personal stories and explanations around these topics are actually like a textbook almost where you can picture the scenarios and indirectly maybe learn from other people's experience. ... It may also prepare us for questions that the parents may have, like whether

they ... about the legalities. Maybe also about their being in two minds about things, whether it's the right thing to do. Yeah, I think having the parents' experience in this book, it's almost like a script. It's sort of dialogue that you might then encounter in real life. So I think other than that, there's no real sort of communication training available in this area, not that I'm aware of. Certainly the college doesn't provide us with a workshop at this stage that I know of.... I find it really helpful because, yeah, we don't get a lot of training with this. Having recorded messages from parents and the questions that might actually come up gives you a heads up. Clinician-6 
the inpatient or outpatient setting. Written resources to assist with clarifying the ethical aspects of such decisions, among other issues, are unavailable for parents and limited for clinicians. ${ }^{66}$ A preliminary literature review revealed that the written resources that do exist for parents address some important issues around EoL ${ }^{21-23}$ but do not explore in great depth a number of issues important in EoL decision making. An important issue for parents to understand, for example, is how and why disagreements arise in the context of EoL discussions and decisions. Unlike such publications, the focus of "Caring Decisions" is on providing information that will assist parents in EoL discussions and information on issues parents weigh up when making decisions about withdrawal/ withholding treatment for their child. We adopted an evidencebased approach to the development of the resources taking into account the literature on parental communication needs, as expressed by parents themselves.

This paper outlined the development and initial piloting of written resources for parents facing EoL decisions. Feedback during consultation and piloting was overwhelmingly positive and identified an additional potential role for such resources in training health professionals in communication and EoL decision making.

Parents were very supportive of the resources and found all of the features appropriate including the content, language, tone, presentation and layout. They felt they had benefitted from reading the resources, particularly because these provided insight into others' experience and prepared them for the future. The importance of having an understanding of what to expect has been highlighted by parents in previous research. ${ }^{67}$ The information in the resources was considered easy to understand, honest, gentle, and tasteful in its approach to difficult content. Honest information, even about dire circumstances, is important for parents, ${ }^{43,45}$ and they have reported that candid and simply expressed information leads to them feeling more in control. ${ }^{4,68}$ A sense of control is important in such contexts, as it contributes to a reduced sense of hopelessness. ${ }^{68}$ Similar positive feedback was obtained from bereaved parents during the consultation process.

Clinicians who provided feedback during the consultation phase and the majority of clinicians interviewed during the pilot evaluation were extremely supportive of all features of the resources including content, language, tone, presentation, and layout. The resources were welcomed by almost all as a valuable tool of benefit to parents, experienced clinicians, and trainees. Most clinicians acknowledged directly or indirectly that the resources would play a positive role in clinician/parent communication. Many particularly liked the questions and phrases provided for parents, as they recognized that these empower parents, who often simply do not know what to ask to obtain further information. ${ }^{33-35}$

The low level of dissemination of 'Caring Decisions' to parents during the study was a limitation of the pilot evaluation. One barrier was the low number of EoL discussions during the study period. Another important barrier was that clinicians appeared to struggle with the appropriateness of discussing research relating to the resource even though they recognized the value of such research. One clinician found that initial concerns about introducing the research were unfounded when parents were approached. Despite their serious circumstances, parents willingly participate in research and see benefits in doing so. ${ }^{69-71}$ As one of the parent-reviewer's noted, the development of such resources and associated research, " ... means that my daughter's battle to live does not go unnoticed to the professionals."

The difficulty clinicians had identifying the appropriate time to give the resource may relate to the complexity and sensitivity of the discussions and may potentially arise from the fact that the concepts of withdrawal or withholding of treatment are introduced indirectly and gradually. Parents have expressed the need for information to be discussed only if parents wish to receive it and when they are ready to receive it, ${ }^{31}$ as too much information can be unwelcome or can arouse fear in parents. ${ }^{72}$ The clinician recommendation in the evaluation study to move the first narrative to a later section of the hardcopy handbook addresses such concerns, as some parents may not yet have reached the stage of considering EoL decisions. Assessing parents' readiness for receipt of information lies squarely within the realm of the clinician/ parent relationship where judgements about a range of issues and the content of communication are routinely made.

The majority of clinicians interviewed expressed their enthusiasm at using the resources in the future and felt that the resources would have a positive impact on parents and clinicians and would facilitate and deepen EoL discussions.

\section{Conclusion}

Written resources to support parents facing EoL decisions were very well received by both the consultation panel and participants in the pilot evaluation study. Despite the low dissemination rates during the study, all aspects of the resources were commented on positively and no aspect of the resources was considered inappropriate. Even though introducing EoL concepts to parents is challenging and the best timing for providing this resource was sometimes difficult to ascertain, clinicians and parents alike appreciated the open, honest approach adopted in the resources. The fact that the resources approach these difficult topics, which some clinicians may hesitate to raise and which some parents may not dare voice, is hoped to provide the opportunity for greater discussion of issues which the literature informs are very important to parents. A further evaluation study is currently underway and will reveal more details about the impact of such a resource on parents' and clinicians' perceptions of EoL discussions.

\section{Acknowledgments}

We would like to acknowledge the assistance provided by Dr. Steve Keeley and Professor Annette Braunack-Mayer in the design of the study. This work was supported by funding from a Channel 7 Children's Research Foundation Grant [13776]. DW was supported for this work by an early career fellowship from the Australian National Health and Medical Research Council [1016641] and in part by a grant from the Wellcome Trust [086041/Z/08/Z].

\section{Author Disclosure Statement}

The authors declare that they have no conflicts of interest.

\section{References}

1. Pinch WJ, Spielman ML: The parents' perspective: Ethical decision-making in neonatal intensive care. J Adv Nurs 1990;15:712-719. 
2. Tan JS, et al.: Addressing parental bereavement support needs at the end of life for infants with complex chronic conditions. J Palliat Med 2012;15:579-584.

3. Hellmann J, et al.: Withdrawal of artificial nutrition and hydration in the Neonatal Intensive Care Unit: Parental perspectives. Arch Dis Child Fetal Neonatal Ed 2013;98:F21(5).

4. Einarsdóttir J: Emotional experts: Parents' views on end-oflife decisions for preterm infants in Iceland. Med Anthropol Q 2009;23:34-50.

5. Berg S: In their own voices: Families discuss end-of-life decision making-part 2. J Pediatr Nurs 2006;32:238-242, 237.

6. Brazy JE, et al.: How parents of premature infants gather information and obtain support. Neonatal Netw 2001;20: 41-48.

7. McHaffie HE, et al.: Deciding for imperilled newborns: Medical authority or parental autonomy? J Med Ethics 2001;27:104-109.

8. Roscigno CI, et al.: Divergent views of hope influencing communications between parents and hospital providers. Qual Health Res 2012;22:1232-1246.

9. Sharman M, Meert ML, Sarnaik AP: What influences parents' decisions to limit or withdraw life support? Pediatr Crit Care Med 2005;6:513-518.

10. Davies B, et al.: Culturally-sensitive information-sharing in pediatric palliative care. Pediatrics 2010;125:e859-e865.

11. Knapp C, et al.: Information seeking behaviors of parents whose children have life-threatening illnesses. Pediatr Blood Cancer 2011;56:805-811.

12. Moro TT, et al.: Parent decision making for life support for extremely premature infants: From the prenatal through end-of-life period. J Perinat Neonatal Nurs 2011;25:52-60.

13. Black BP: Truth telling and severe fetal diagnosis: A virtue ethics perspective. J Perinat Neonatal Nurs 2011;25:13-20.

14. Thiele P: Going against the grain: Liam's story. J Paediatr Child Health 2011;47:656-658.

15. Bingham A, Correa VI, Huber JJ: Mothers' voices: Coping with their children's initial disability diagnosis. Infant Ment Health J 2012;33:372-385.

16. Kowalski WJ, et al.: Communicating with parents of premature infants: Who is the informant? J Perinatol 2006;26:44-48.

17. Dhillon AS, et al.: Internet use and perceptions of information reliability by parents in a neonatal intensive care unit. J Perinatol 2003;23:420-424.

18. Azoulay E, et al.: Impact of a family information leaflet on effectiveness of information provided to family members of intensive care unit patients: A multicenter, prospective, randomized, controlled trial. Am J Respir Crit Care Med 2002; 165:438-442.

19. Lautrette A, et al.: A communication strategy and brochure for relatives of patients dying in the ICU. N Engl $\mathbf{J}$ Med 2007;356:469-478.

20. Dokken DL: In their own voices: Families discuss end-oflife decision making-part 1 . Interview by Elizabeth Ahmann. J Pediatr Nurs 2006;32:173-175.

21. Cole A, Pradhan F, Shannon C: Making Critical Care Decisions for Your Baby. London: Bliss Publications, 2010. www.togetherforshortlives.org.uk/assets/0000/1111/Bliss_-_ Making_Critical_Care_Decisions_for_Your_Baby.pdf.

22. Smith J, Kvinsland B: Life's Toughest Moments: A Parent's Guide When Facing End of Life Decisions with Their Child. CP \& Publishing, 2006.

23. Dunn H: Hard Choices for Loving People: CPR, Artificial Feeding, Comfort Care, and the Patient with a LifeThreatening Illness, 5th ed. A \& A Publishers, 2009.
24. Wilkinson D, et al.: Caring Decisions: A Handbook For Parents Facing End-Of-Life Decisions For Their Child. Melbourne: The Royal Children's Hospital, 2013.

25. Wilkinson D, et al.: Caring Decisions: A Handbook For Parents Facing End-Of-Life Decisions For Their Child. www.rch.org.au/caringdecisions.

26. Xafis V, Wilkinson D, Sullivan J: What information do parents need when facing end-of-life decisions for their child? A meta-synthesis of parental feedback. BMC Palliative Care 2015;14.

27. Sullivan JE: Parents' views and experiences of end-of-life decision-making for their child. The University of Melbourne: Melbourne School of Population and Global Health, Faculty of Medicine, Dentistry \& Health Sciences, 2012. hdl.handle.net/11343/38154.

28. Kavanaugh $\mathrm{K}$, et al.: Life support decisions for extremely premature infants: Report of a pilot study. J Pediatr Nurs 200;20:347-359.

29. Keenan HT, Doron MW, Seyda BA: Comparison of mothers' and counselors' perceptions of predelivery counseling for extremely premature infants. Pediatrics 2005;116:104-111.

30. McHaffie HE, Lyon AJ, Hume R: Deciding on treatment limitation for neonates: The parents' perspective. Eur J Pediatr 2000;160:339-344.

31. Brinchmann SB, Førde R, Nortvedt P: What matters to the parents? A qualitative study of parents' experiences with life-and-death decisions concerning their premature infants. Nurs Ethics 2002;9:388-404.

32. Schlomann P, Fister S: Parental perspectives related to decision-making and neonatal death. J Pediatr Nurs 1995;21:243-247,254.

33. Davies B, Connaughty S: Pediatric end-of-life care: Lessons learned from parents. J Nurs Adm 2002;32:5-6.

34. Pinch WJ, Winifred J, Spielman ML: Ethics in the neonatal intensive care unit: Parental perceptions at four years postdischarge. ANS Adv Nurs Sci 1996;19:72-85.

35. Pinch WJ, Spielman ML: Parental perceptions of ethical issues post-NICU discharge. West J Nurs Res 1993;15:422437; discussion 438.

36. Boss RD, et al.: Values parents apply to decision-making regarding delivery room resuscitation for high-risk newborns. Pediatrics 2008;122:583-589.

37. Meert KL, et al.: Parents' perspectives on physician-parent communication near the time of a child's death in the pediatric intensive care unit. Pediatr Crit Care Med 2008;9:2-7.

38. Carnevale FA, et al.: Parental involvement in treatment decisions regarding their critically ill child: A comparative study of France and Quebec. Pediatr Crit Care Med 2007;8:337342.

39. Rini A, Loriz L: Anticipatory mourning in parents with a child who dies while hospitalized. J Pediatr Nurs 2007;22:272-282.

40. Raines DA: Suspended mothering: Women's experiences mothering an infant with a genetic anomaly identified at birth. Neonatal Netw 1999;18:35-39.

41. Scott LD: Perceived needs of parents of critically ill children. J Soc Pediatr Nurs 1998;3:4-12.

42. Caeymaex L, et al.: Living with a crucial decision: A qualitative study of parental narratives three years after the loss of their newborn in the NICU. PLoS ONE 2011;6.

43. Brosig CL, et al.: Infant end-of-life care: The parents' perspective. J Perinatol 2007;27:510-516.

44. Kavanaugh K: Parents' experience surrounding the death of a newborn whose birth is at the margin of viability. J Obstet Gynecol Neonatal Nurs 1997;26:43-51. 
45. Wocial LD: Life support decisions involving imperiled infants. J Perinat Neonatal Nurs 2000;14:73-86.

46. Einaudi MA, et al.: Parental experience following perinatal death: Exploring the issues to make progress. Eur J Obstet Gynecol Reprod Biol 2010;151:143-148.

47. Widger K, Picot C: Parents' perceptions of the quality of pediatric and perinatal end-of-life care. Pediatric Nurs 2008;34:53-58.

48. Meyer EC, et al.: Improving the quality of end-of-life care in the pediatric intensive care unit: Parents' priorities and recommendations. Pediatrics 2006;117:649-657.

49. Côté-Arsenault D, Denney-Koelsch E: "My baby is a person": Parents' experiences with life-threatening fetal diagnosis. J Palliat Med 2011;14:1302-1308.

50. Orfali K, Gordon EJ: Autonomy gone awry: A crosscultural study of parents' experiences in neonatal intensive care units. Theoret Med Bioeth 2004;25:329-365.

51. Lundqvist A, Nilstun T, Dykes AK: Neonatal end-of-life care in Sweden: The views of Muslim women. J Perinat Neonatal Nurs 2003;17:77-86.

52. Caeymaex L, et al.: Perceived role in end-of-life decision making in the NICU affects long-term parental grief response. Arch Dis Child Fetal Neonatal Ed 2012;98:F26-F31.

53. Haward MF, et al.: Effects of description of options on parental perinatal decision-making. Pediatrics 2012;129:891897.

54. Sayeed S, et al.: A Saudi family making end-of-life decisions in the PICU. Pediatrics 2012;129:764-768.

55. Partridge JC, et al.: International comparison of care for very low birth weight infants: Parents' perceptions of counseling and decision-making. Pediatrics 2005;116:e263-e271.

56. Contro N, et al.: Family perspectives on the quality of pediatric palliative care. Arch Pediatr Adolesc Med 2002;156: 14-19.

57. Streiner DL, et al.: Attitudes of parents and health care professionals toward active treatment of extremely premature infants. Pediatrics 2001;108:152-157.

58. Michelson KN, et al.: Parental views on withdrawing lifesustaining therapies in critically ill children. Arch Pediatr Adolesc Med 2009;163:986-992.

59. Meyer EC, et al.: Parental perspectives on end-of-life care in the pediatric intensive care unit. Crit Care Med 2002;30:226-231.

60. Kirschbaum MS: Life support decisions for children: What do parents value? ANS Adv Nurs Sci 1996;19:51-71.

61. Xafis V, et al.: Balancing obligations: Should written information about life-sustaining treatment be neutral? J Med Ethics 2015;41:234-239.
62. Lee KJ, Tieves K, Scanlon MC: Alterations in end-of-life support in the pediatric intensive care unit. Pediatrics 2010; 126:e859-e864.

63. Berger TM, Hofer A: Causes and circumstances of neonatal deaths in 108 consecutive cases over a 10-year period at the Children's Hospital of Lucerne, Switzerland. Neonatology 2009;95:157-163.

64. Verhagen AAE, et al.: Categorizing neonatal deaths: A cross-cultural study in the United States, Canada, and The Netherlands. J Pediatr 2010;156:33-37.

65. Wilkinson DJ, et al.: Death in the neonatal intensive care unit: Changing patterns of end of life care over two decades. Arch Dis Child Fetal Neonatal Ed 2006;91:F268-F271.

66. Nuffield Council on Bioethics: Critical care decisions in fetal and neonatal medicine: Ethical issues. London: Nuffield Council on Bioethics, 2006. nuffieldbioethics.org/ wp-content/uploads/2014/07/CCD-web-version-22-June07-updated.pdf.

67. Branchett K, Stretton J: Neonatal palliative and end of life care: What parents want from professionals. J Neonatal Nurs 2012;18:40-44.

68. Charchuk M, Simpson C: Hope, disclosure, and control in the neonatal intensive care unit. Health Comm 2005;17: 191-203.

69. Michelson KN, et al.: Parents' reactions to participating in interviews about end-of-life decision making. J Palliat Med 2006;9:1329-1338.

70. Buckle JL, Dwyer SC, Jackson M: Qualitative bereavement research: Incongruity between the perspectives of participants and research ethics boards. Int J Soc Rec Meth 2010;13: 111-125.

71. Hynson JL, et al.: Research with bereaved parents: A question of how not why. Palliat Med 2006;20:805-811.

72. Arockiasamy V, Holsti L, Albersheim S: Fathers' experiences in the neonatal intensive care unit: A search for control. Pediatrics 2008;121:e215-e222.

Address correspondence to:

Vicki Xafis, BA (Languages, H1 Hons-Linguistics), RSA (DTEFLA), M Bioethics, PhD The Sydney Children's Hospitals Network Level 4, Executive Unit

Corner Hawkesbury Road \& Hainsworth Street

Locked Bag 4001

Westmead NSW 2145

Australia

E-mail: vicki.xafis@adelaide.edu.au 